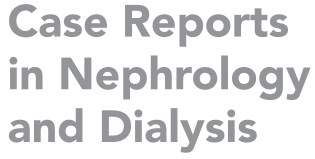

Case Reports and Dialysis

\title{
Etanercept-Induced Anti-Glomerular Basement Membrane Disease
}

\author{
Saif Al-Chalabi ${ }^{a}$ Henry H.L. Wu ${ }^{a, b}$ Rajkumar Chinnadurai ${ }^{b, c}$ \\ Arvind Ponnusamy ${ }^{a, b}$ \\ aDepartment of Renal Medicine, Royal Preston Hospital, Lancashire Teaching Hospitals \\ NHS Foundation Trust, Fulwood, UK; b Faculty of Biology, Medicine and Health, University \\ of Manchester, Manchester, UK; ' Departement of Renal Medicine, Salford Royal NHS \\ Foundation Trust, Salford, UK
}

\section{Keywords}

Tumour necrosis factor-alpha/antagonists and inhibitors · Etanercept · Anti-glomerular basement membrane disease

\begin{abstract}
Anti-glomerular basement membrane (anti-GBM) disease is a rare form of small-vessel vasculitis that typically causes rapidly progressive glomerulonephritis with or without alveolar haemorrhage. Previously, there has only been one reported case of tumour necrosis factor- $\alpha$ (TNF- $\alpha$ ) antagonist-induced anti-GBM disease. Here, we describe the first reported case of etanercept-induced anti-GBM disease. A 55-year-old Caucasian man was referred to our tertiary specialist renal centre with a history of painless macroscopic haematuria. The patient has been receiving weekly etanercept injections over the past 12 months for psoriatic arthropathy. The serum immunology panel results highlighted a significantly raised anti-GBM titre (370.1 $U)$. Etanercept was stopped, and the patient was empirically commenced on pulsed methylprednisolone, cyclophosphamide, and plasma exchange. A renal biopsy showed crescentic glomerulonephritis. Few days after admission, he tested positive for coronavirus disease 2019 (COVID-19), and a decision was made to withhold cyclophosphamide. There was further decline in renal function with hyperkalaemia for which he received 2 sessions of haemodialysis. He was restarted on cyclophosphamide upon discharge. The patient was switched to rituximab treatment afterwards as he developed leucopenia 2 weeks following the commencement of cyclophosphamide. The serum creatinine level continued to improve and remained dialysisindependent. In conclusion, with the increased use of etanercept and other TNF- $\alpha$ antagonists, the prescribing clinician must be aware of the rare but life-threatening drug-induced vasculitis. We recommend careful monitoring of renal indices with the use of this class of medications.
\end{abstract}




\section{Introduction}

Anti-glomerular basement membrane (anti-GBM) disease is a rare form of small-vessel vasculitis that typically causes rapidly progressive glomerulonephritis with or without alveolar haemorrhage. The exact cause of its immune trigger is not well understood. It has been hypothesized that environmental factors can cause clusters of anti-GBM disease in genetically susceptible individuals [1].

Tumour necrosis factor- $\alpha$ (TNF- $\alpha$ ) antagonists such as adalimumab, infliximab, and etanercept are commonly used to treat inflammatory diseases such as psoriasis, rheumatoid arthritis, and inflammatory bowel disease. Previously, there has only been one reported case of TNF- $\alpha$ antagonist-induced anti-GBM disease, where the patient received adalimumab for over 4 years to manage his rheumatoid arthritis [2]. We describe the first reported case of etanercept-induced anti-GBM disease.

\section{Case Presentation}

A 55-year-old Caucasian man was referred to the local district general hospital by his general practitioner with a 3-week history of sudden-onset painless macroscopic haematuria. The patient has been receiving weekly etanercept injections over the past 12 months for psoriatic arthropathy, which was diagnosed in 2017 when he initially presented with oligoarthritis in his left knee and elbow. Etanercept injections were effective in managing his psoriatic arthritis symptoms in remission. The patient received methotrexate treatment prior to initiation of etanercept. Other than psoriatic arthropathy, there was no history of renal disease or other significant past medical history. The patient is a non-smoker and denied previous use of anabolic steroids or other synthetic bodybuilding supplements.

In view of the severity of his renal function derangement upon admission (serum creatinine $4.7 \mathrm{mg} / \mathrm{dL}$ ), the patient was transferred to our tertiary specialist renal centre. Upon our review, he denied clinical symptoms such as haemoptysis, epistaxis, or appearances of skin rash manifestations. No features of active arthritis were detected on physical examination. Though there was mild pitting oedema on both ankles, clear chest sounds were noted on auscultation. Urinalysis showed haematoproteinuria (blood 3+, protein $1+$ ). Chest $\mathrm{X}$-ray did not identify abnormal radiological signs with clear lung fields and normal mediastinal and cardiac shadows. A further contrast computed tomography scan showed normal-sized kidneys without evidence of obstructive disease. The serum immunology panel results highlighted a significantly raised anti-GBM titre (370.1 U). Etanercept was stopped, and the patient was empirically commenced on 3 doses of pulsed intravenous (IV) methylprednisolone (250 mg each), oral cyclophosphamide (2 $\mathrm{mg} / \mathrm{kg} /$ day), and plasma exchange via an intravascular catheter. A renal biopsy was performed which on pathological examination showed cellular crescents in 14 out of 28 glomeruli with the presence of moderate interstitial inflammation (shown in Fig. 1). Falling anti-GBM titres were observed in the initial days following treatment initiation, though serum creatinine levels continued to rise (shown in Fig. 2).

The patient tested positive for coronavirus disease 2019 (COVID-19) on day 5 following admission on a routine surveillance throat swab polymerase chain reaction, which was performed as he was in close contact with another patient who tested positive. After the positive COVID-19 results, the decision was made to withhold cyclophosphamide following discussion with the patient on the risks of immunosuppressive treatment with a positive COVID-19 diagnosis. Treatment with $30 \mathrm{mg} /$ day oral prednisolone and plasma exchange continued with monitoring of respiratory symptoms. During the next 11 days of inpatient

\section{Karger'}


Fig. 1. Cellular crescent with interstitial inflammatory changes in light microscopy. (Arrows show crescents of similar age.)
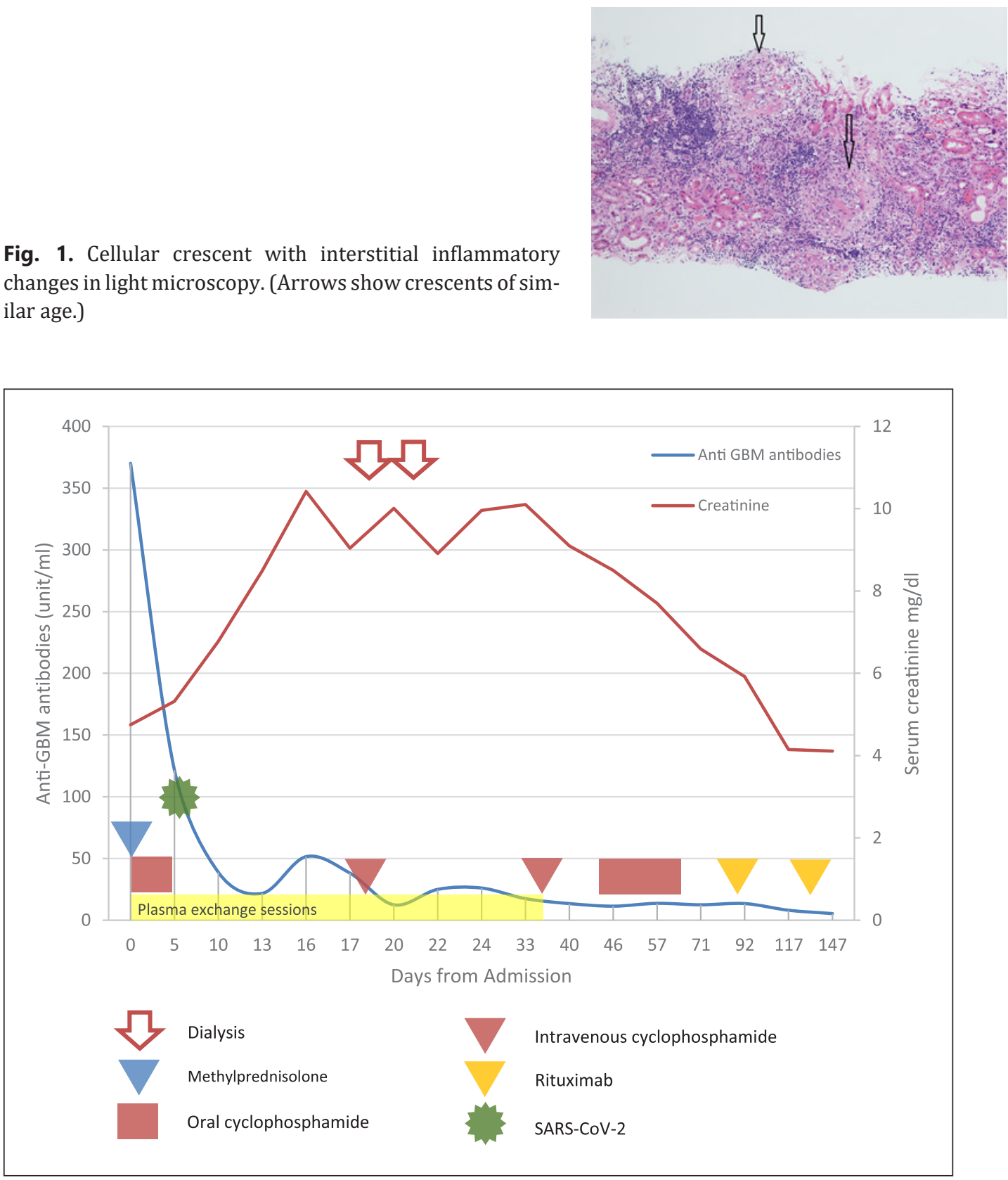

Fig. 2. Progression of anti-GBM titre and serum creatinine levels from day 0 to day 147 following initial hospital admission. GBM, glomerular basement membrane.

admission, there was further decline in renal function with hyperkalaemia, for which he received 2 sessions of in-centre haemodialysis.

On day 16 following admission, the patient recovered clinically, and he received $1 \mathrm{~g}$ IV cyclophosphamide prior to home discharge the same day. He received another $1 \mathrm{~g}$ IV cyclophosphamide in the community under supervision before switching to an oral preparation of cyclophosphamide. The patient was switched to rituximab treatment afterwards and received 2 doses ( $1 \mathrm{~g}$ per dose). This was due to the development of leucopenia 2 weeks following the commencement of oral cyclophosphamide. By that point, full tissue typing results were 
available, which showed the patient having the HLA-DRB1-15 allele, conferring a high susceptibility of him developing anti-GBM disease [3].

The patient's serum creatinine levels decreased by almost two-thirds from peak admission levels at 5 months following hospital discharge, and he is under close follow-up review from the renal unit. Currently, there is no further immunosuppression planned as his anti-GBM antibody titres remain negative. The patient did not require further dialysis, and his psoriatic arthritis remained in remission without further requirements for etanercept or another form of disease-modifying anti-rheumatic therapy.

\section{Discussion}

TNF- $\alpha$, released into human circulation in its functional 17-kDa soluble form, is a cytokine primarily involved in homoeostasis of the body's immune cells [4]. TNF- $\alpha$ is chiefly produced by activated macrophages, although T-helper cells and natural killer cells amongst other cell types contribute towards its production. As an acute phase reactant, excess TNF- $\alpha$ production promotes systemic inflammation [5]. Collectively, TNF receptor (TNFR) 1 and TNFR2 are markers of the TNF pathway [6]. TNFR1 is detected in most cell types and could be activated by both the membrane-bound and trimeric soluble forms of TNF- $\alpha$ [7]. TNFR2 is selectively located in cells of the immune system - oligodendrocytes, astrocytes, T cells, endothelial cells, human mesenchymal stem cells, myocytes, and thymocytes. It will usually only respond towards homotrimeric, membrane-bound forms of TNF- $\alpha$ [8-14]. TNF- $\alpha$ either exists as a free protein or is bound to these circulating receptors in plasma [6].

There is dysregulation of TNF- $\alpha$ in the pathophysiology of various autoimmune disorders, namely, rheumatoid arthritis, ankylosing spondylitis, and psoriasis-associated conditions. Excess TNF- $\alpha$ also plays a key role in renal inflammation. In healthy individuals, TNFR1 could be detected within the normal glomerular endothelial structure, situated usually at the Golgi apparatus, whilst TNF- $\alpha$ and TNFR2 are not expected to be found [15]. During an inflammatory response, TNF- $\alpha$, TNFR1, and TNFR2 would be expressed and disseminated across the glomerular and tubular cellular structures [16]. Animal studies have demonstrated TNF- $\alpha$ recruitment within the intrinsic renal structure prior to its direct effects of promoting kidney injury [17]. TNF- $\alpha$ is a pleotropic cytokine and its immunomodulatory and anti-inflammatory activities through immune cell apoptosis should be recognized [18]. TNF- $\alpha$ antagonists have been the conventional pharmacological treatment for autoimmune and immune-mediated diseases where a high level of TNF- $\alpha$ is present, where it is a good target for inflammatory suppression. Anti-TNF- $\alpha$ therapy is either a monoclonal antibody or, in the case patient's scenario, a circulating receptor fusion protein such as etanercept. Monoclonal antibodies to TNF- $\alpha$, such as infliximab and adalimumab, could bind to both soluble and transmembrane TNF- $\alpha$, using this mechanism to downregulate TNF- $\alpha$-inflammatory activity including adhesion molecule expression, cytokine production, neutrophil activity, dendritic cell production, matrix metalloproteinase production, and osteoclast differentiation. Most monoclonal antibodies to TNF- $\alpha$ can lyse cells which express TNF- $\alpha$ in the presence of complement [19]. Etanercept has a much longer half-life in the circulation as opposed to the simple soluble TNF receptor. As a fusion protein, etanercept functions as a decoy receptor which binds to TNF- $\alpha$, thereby deactivating TNF- $\alpha$ and blunting its effects of inducing an inflammatory response [20].

The associations between etanercept and intrinsic renal disease are complex. Historically, there have been multiple findings of glomerulonephritis presentations related to etanercept use (Table 1). Previously reported cases include necrotizing crescenteric glomerulonephritis, membranous nephropathy, ANCA-positive glomerulonephritis, minimal change disease, lupus nephritis, Henoch-Schonlein purpura with glomerulonephritis, extracapillary glomerulonephritis,

\section{Karger'}


Case Reports

in Nephrology and Dialysis
Case Rep Nephrol Dial 2021;11:292-300 DOI: $10.1159 / 000518984$

Al-Chalabi et al.: Etanercept-Induced Anti-Glomerular Basement Membrane Disease

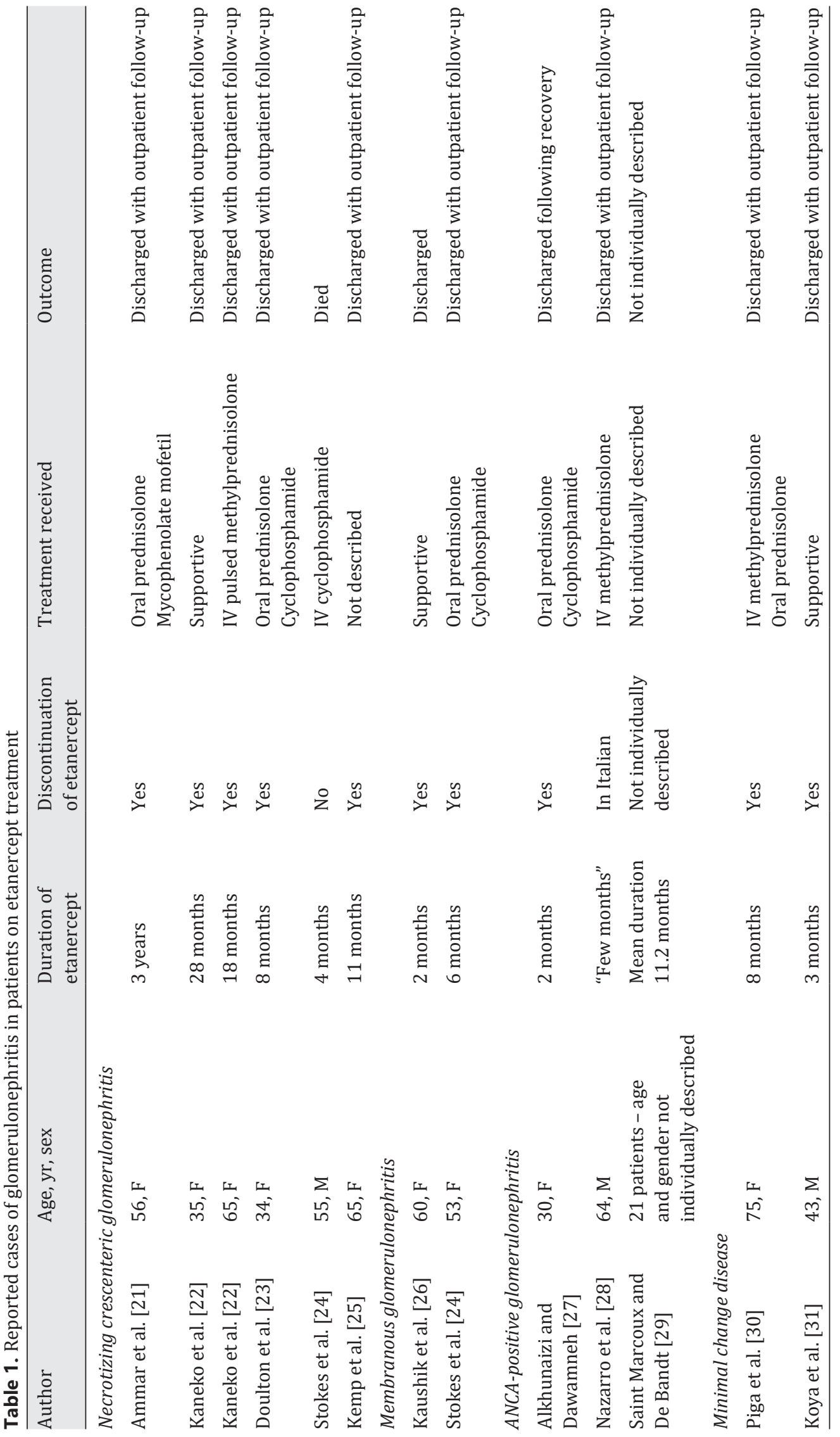


Case Reports

in Nephrology and Dialysis
Case Rep Nephrol Dial 2021;11:292-300

DOI: $10.1159 / 000518984$

(c) 2021 The Author(s).P
www.karger.com/cnd

Al-Chalabi et al.: Etanercept-Induced Anti-Glomerular Basement Membrane Disease

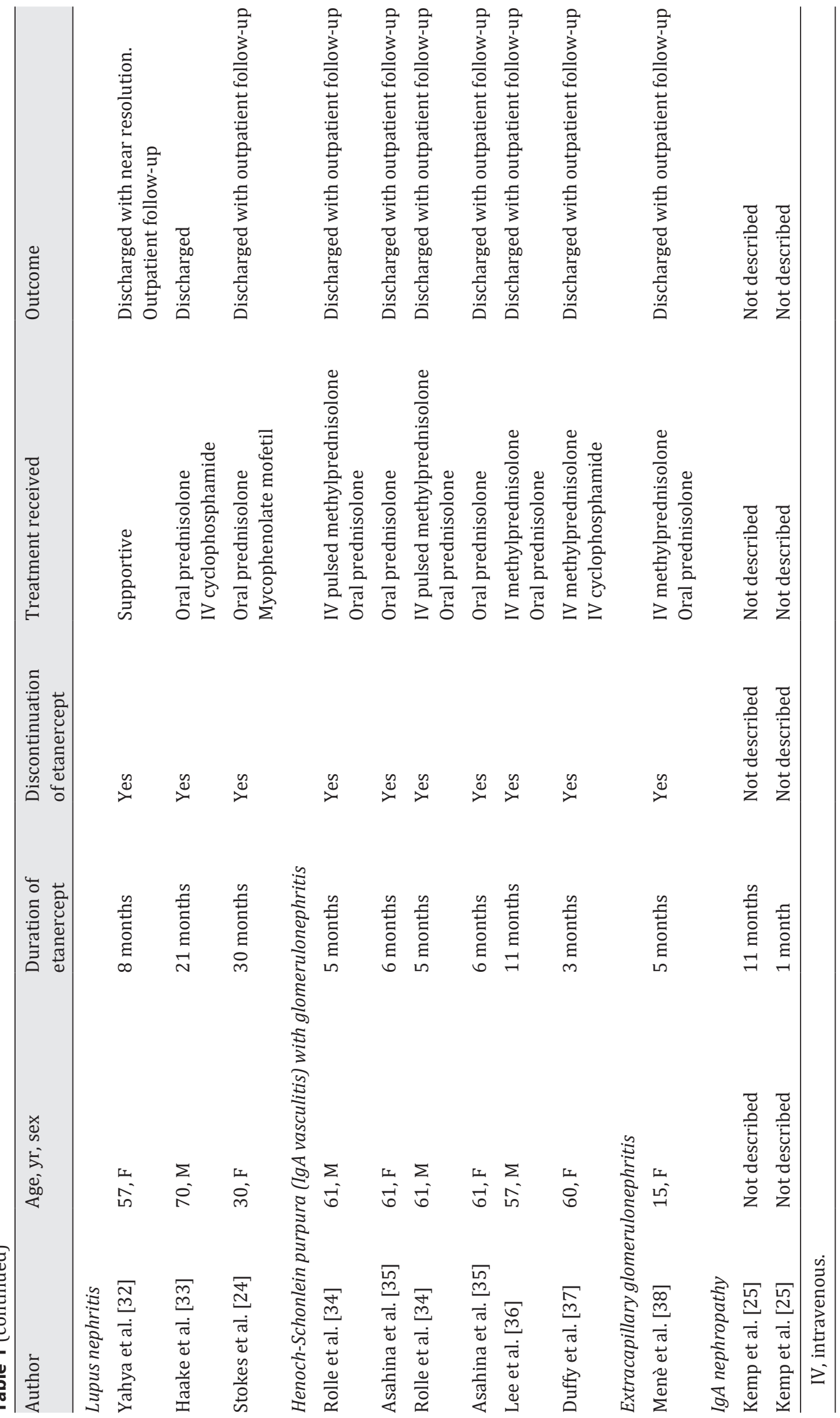

Karger' 
and IgA nephropathy [21-38]. The pathophysiology of how etanercept leads to crescenteric glomerulonephritis remains unclear, but the plausible mechanisms would include a genetic predisposition, epigenetic dysregulation, and drug biotransformation. COVID-19-associated anti-GBM disease has been reported recently, but the negative COVID-19 polymerase chain reaction test and antibody serological test on the day of admission ruled out this possibility [39].

Cases describing manifestations of anti-GBM disease in patients receiving etanercept have not been published previously. Although the manifestation of anti-GBM disease is associated with various factors, reported cases of autoimmune glomerular injury following etanercept treatment $>12$ months suggest the possibility of a temporal relationship between etanercept treatment and anti-GBM disease [21, 22, 24, 33]. In our case, a renal biopsy was done even before we received the anti-GBM titre result, and hence, an immunofluorescence on the biopsy was not routinely performed. We acknowledge that this may limit the diagnosis of anti-GBM disease. However, the following points strongly supported the diagnosis of anti-GBM disease: (1) the crescents in the haematoxylin and eosin stain of the biopsy were all in similar age, (2) the high specificity of the anti-GBM antibody assay used in this case (specifically directed to type IV collagen alpha 3), (3) a genetic predisposition of our patient for anti-GBM disease by carrying the HLA-DRB1-15 allele, (4) absence of a history or clinical features of Alport's syndrome, and (5) a particularly good response to treatment (decline in anti-GBM titres and renal function recovery).

\section{Acknowledgements}

The authors would like to thank Dr. Beena Nair, consultant histopathologist, Royal Preston Hospital, for providing the image in Figure 1.

\section{Statement of Ethics}

Written informed consent from the patient has been obtained for publication including images. The research was conducted ethically in accordance with the World Medical Association Declaration of Helsinki. The study is exempt from ethical committee approval as it is not required for a single case report.

\section{Conflict of Interest Statement}

The authors have no conflicts of interest to declare.

\section{Funding Sources}

There was no external funding for this work.

\section{Author Contributions}

S.A.-C. and A.P. obtained the history, performed the physical examinations, and obtained investigation reports. S.A.-C. and H.H.L.W. wrote the initial draft. R.C. and A.P. reviewed the paper and revised it critically. All authors read and approved the final manuscript. 


\section{Data Availability Statement}

All data generated or analysed during this study are included in this article. Further enquiries can be directed to the corresponding author.

\section{References}

1 Canney M, O’Hara PV, McEvoy CM, Medani S, Connaughton DM, Abdalla AA, et al. Spatial and temporal clustering of anti-glomerular basement membrane disease. Clin J Am Soc Nephrol. 2016;11(8):1392-9.

2 Heron V, Nicholson M, Wilkinson S, Young A, Govindarajulu S, Venuthurpalli S. Anti-glomerular basement membrane-antibody disease in a patient treated with adalimumab for rheumatoid arthritis. J Clin Sci Res. 2020;9:124.

3 Phelps RG, Rees AJ. The HLA complex in goodpasture's disease: a model for analyzing susceptibility to autoimmunity. Kidney Int. 1999;56:1638-53.

4 Lorenzen I, Trad A, Grötzinger J. Multimerisation of a disintegrin and metalloprotease protein-17 (ADAM17) is mediated by its EGF-like domain. Biochem Biophys Res Commun. 2011;415:330-6.

5 Speeckaert MM, Speeckaert R, Laute M, Vanholder R, Delanghe JR. Tumor necrosis factor receptors: biology and therapeutic potential in kidney diseases. Am J Nephrol. 2012;36:261-70.

6 Richter C, Messerschmidt S, Holeiter G, Tepperink J, Osswald S, Zappe A, et al. The tumor necrosis factor receptor stalk regions define responsiveness to soluble versus membrane-bound ligand. Mol Cell Biol. 2012; 32(13):2515-29.

7 Cabal-Hierro L, Lazo PS. Signal transduction by tumor necrosis factor receptors. Cell Signal. 2012;24:1297305.

8 Inukai T, Uchida K, Nakajima H, Yayama T, Kobayashi S, Mwaka ES, et al. Tumor necrosis factor-alpha and its receptors contribute to apoptosis of oligodendrocytes in the spinal cord of spinal hyperostotic mouse (twy/ twy) sustaining chronic mechanical compression. Spine. 1976;34:2848-57. 2009

9 Yan M, Xia C, Cheng C, Shao X, Niu S, Liu H, et al. The role of TNF-alpha and its receptors in the production of Src-suppressed C kinase substrate by rat primary type-2 astrocytes. Brain Res. 2007;1184:28-37.

10 Chen X, Oppenheim JJ. Contrasting effects of TNF and anti-TNF on the activation of effector T cells and regulatory T cells in autoimmunity. FEBS Lett. 2011;585:3611-8.

11 Ding B, Kirkiles-Smith NC, Pober JS. FOXO3a regulates oxygen-responsive expression of tumor necrosis factor receptor 2 in human dermal microvascular endothelial cells. J Biol Chem. 2009;284:19331-9.

12 Kelly ML, Wang M, Crisostomo PR, Abarbanell AM, Herrmann JL, Weil BR, et al. TNF receptor 2, not TNF receptor 1 , enhances mesenchymal stem cell-mediated cardiac protection following acute ischemia. Shock. 2010;33:602-7.

13 Defer N, Azroyan A, Pecker F, Pavoine C. TNFR1 and TNFR2 signaling interplay in cardiac myocytes. J Biol Chem. 2007;282:35564-73.

14 Grell M, Becke FM, Wajant H, Männel DN, Scheurich P. Tumor necrosis factor (TNF) receptor type 2 mediates thymocyte proliferation independently of TNF receptor type 1. Eur J Immunol. 1998;28:257-63.

15 Al-Lamki RS, Wang J, Skepper JN, Thiru S, Pober JS, Bradley JR. Expression of tumor necrosis factor receptors in normal kidney and rejecting renal transplants. Lab Invest. 2001;81:1503-15.

16 Baud L, Ardaillou R. Tumor necrosis factor in renal injury. Miner Electrolyte Metab. 1995;21:336-41.

17 Taubitz A, Schwarz M, Eltrich N, Lindenmeyer MT, Vielhauer V. Distinct contributions of TNF receptor 1 and 2 to TNF-induced glomerular inflammation in mice. PLoS One. 2013;8:e68167.

18 Liao YC, Liang WG, Chen FW, Hsu JH, Yang JJ, Chang MS. IL-19 induces production of IL-6 and TNF-alpha and results in cell apoptosis through TNF-alpha. J Immunol. 2002;169(8):4288-97.

19 Levin AD, Wildenberg ME, van den Brink GR. Mechanism of action of anti-TNF therapy in inflammatory bowel disease. J Crohns Colitis. 2016;10:989-97.

20 Tan JK, Aphale A, Malaviya R, Sun Y, Gottlieb AB. Mechanisms of action of etanercept in psoriasis. J Investig Dermatol Symp Proc. 2007;12:38-45.

21 Ammar A, Zafar Ahmed Mahmood HH, Shahid Z, Jain R, Chen G. Etanercept-associated nephropathy. Cureus. 2019;11(8):e5419.

22 Kaneko K, Nanki T, Hosoya T, Mizoguchi F, Miyasaka N. Etanercept-induced necrotizing crescentic glomerulonephritis in two patients with rheumatoid arthritis. Mod Rheumatol. 2010;20:632-6.

23 Doulton TW, Tucker B, Reardon J, Velasco N. Antineutrophil cytoplasmic antibody-associated necrotizing crescentic glomerulonephritis in a patient receiving treatment with etanercept for severe rheumatoid arthritis. Clin Nephrol. 2004;62:234-8.

24 Stokes MB, Foster K, Markowitz GS, Ebrahimi F, Hines W, Kaufman D, et al. Development of glomerulonephritis during anti-TNF-alpha therapy for rheumatoid arthritis. Nephrol Dial Transplant. 2005;20: 1400-6.

25 Kemp E, Nielsen H, Petersen LJ, Gam AN, Dahlager J, Horn T, et al. Newer immunomodulating drugs in rheumatoid arthritis may precipitate glomerulonephritis. Clin Nephrol. 2001;55:87-8. 
26 Kaushik P, Rahmani M, Ellison W. Membranous glomerulonephritis with the use of etanercept in ankylosing spondylitis. Ann Pharmacother. 2011;45(12):e62.

27 Alkhunaizi AM, Dawamneh MF. ANCA-positive crescentic glomerulonephritis in a patient with rheumatoid arthritis treated with anti-tumor necrosis factor alpha. Int J Rheum Dis. 2017;20:1843-7.

28 Nazzaro P, Battaglia R, D’Altri C, Marangi AL, Perniola M, Rodio A, et al. Insorgenza di glomerulonefrite a depositi mesangiali di IgA e positività di p-ANCA GIN: Anno 33-Vol. 2-Marzo-Aprile 2016 Nephromeet. G Ital di Nefrol. 2016;33:1-7.

29 Saint Marcoux B, De Bandt M. Vasculitides induced by TNF $\alpha$ antagonists: a study in 39 patients in France. Jt Bone Spine. 2006;73:710-3.

30 Piga M, Chessa E, Ibba V, Mura V, Floris A, Cauli A, et al. Biologics-induced autoimmune renal disorders in chronic inflammatory rheumatic diseases: systematic literature review and analysis of a monocentric cohort. Autoimmun Rev. 2014;13:873-9.

31 Koya M, Pichler R, Jefferson JA. Minimal-change disease secondary to etanercept. Clin Kidney J. 2012;5:420-3.

32 Yahya TM, Dhanyamraju S, Harrington TM, Prichard JW. Spontaneous resolution of lupus nephritis following withdrawal of etanercept. Ann Clin Lab Sci. 2013;43:447-9.

33 Haake H, Köneke J, Amann K, Vom Dahl J, Janssen U. Entwicklung eines systemischen lupus erythematodes mit fokaler proliferativer lupusnephritis unter einer Anti-TNF- $\alpha$-therapie bei psoriasisarthritis. Med Klin. 2007; 102(10):852-7.

34 Rolle AS, Zimmermann B, Poon SH. Etanercept-induced Henoch-Schönlein purpura in a patient with ankylosing spondylitis. J Clin Rheumatol. 2013;19:90-3.

35 Asahina A, Ohshima N, Nakayama H, Shirai A, Juji T, Matsui T. Henoch-Schönlein purpura in a patient with rheumatoid arthritis receiving etanercept. Eur J Dermatol. 2010;20:521-2.

36 Lee A, Kasama R, Evangelisto A, Elfenbein B, Falasca G. Henoch-Schönlein purpura after etanercept therapy for psoriasis. J Clin Rheumatol. 2006;12:249-51.

37 Duffy TN, Genta M, Moll S, Martin PY, Gabay C. Henoch Schönlein purpura following etanercept treatment of rheumatoid arthritis. Clin Exp Rheumatol. 2006;24:S106.

38 Menè P, Franeta AJ, Conti G, Stoppacciaro A, Chimenz R, Fede A, et al. Extracapillary glomerulonephritis during etanercept treatment for juvenile psoriatic arthritis. Clin Exp Rheumatol. 2010;28:91-3.

39 Kudose S, Batal I, Santoriello D, Xu K, Barasch J, Peleg Y, et al. Kidney biopsy findings in patients with COVID-19. J Am Soc Nephrol. 2020;31:1959-68. 